Bentham open
CrossMark
Content list available at: www.benthamopen.com/PHARMSCI/
DOI: $10.2174 / 1874844901603010182$

REVIEW ARTICLE

\title{
Study of Effect of Different Factors in Formulation of Micro and Nanospheres with Solvent Evaporation Technique
}

\author{
Gunjan Subedi ${ }^{*}$, Ashwinee Kumar Shrestha $^{2}$ and Shailendra Shakya ${ }^{2}$ \\ ${ }^{\prime}$ Qmed Formulations Pvt. Ltd and Department of Pharmacy, Kathmandu University, Dhulikhel, Nepal \\ ${ }^{2}$ Department of Pharmacy, Kathmandu University, Dhulikhel, Nepal
}

Received: December 22, 2015

Revised: June 16, 2016

Accepted: June 20, 2016

\begin{abstract}
:
Background:

There are various methods of formulation of micro and nanospheres such as solvent evaporation, solvent removal, polymerization, hot-melt encapsulation, coacervation, phase/wet inversion, spray drying, spray congealing etc. Amongst these all, solvent evaporation is one of the most widely used, researched, easy, accessible methods and for which many patents have been applied. It is thus imperative to understand the basics of effect of formulation variables and design of solvent evaporation method which will be covered in this review article.
\end{abstract}

\section{Objective:}

To discuss the various formulation factors while designing the robust micro and nanospherical systems with better morphology, entrapment and release of the drugs.

\section{Method:}

Systematic analysis of the relevant literature, bibliographies, and interactions with investigators.

\section{Results:}

From the investigation of different literatures, it was found that various factors of solvent evaporation technique may be controlled in order to design the micro and nanospheres of suitable morphology, entrapment and release characters.

\section{Conclusion:}

Various factors like type of polymer used, weight, viscosity, hydrophilicity, concentration, polymer ratio, stirring speed, emulsifier concentration, concentration of cross-linking agents, type of solvent used, rate of addition of solvent etc. Affect the yield, morphology, release and entrapment of the drug inside the system. Hence, these factors play crucial role in the design of a robust micro and nanospherical system.

Keywords: Entrapment, Microparticles, Nanoparticles, Polymer erosion.

\section{INTRODUCTION}

Micro and nanospherical drug delivery systems are the fields of increasing concern in the present pharmaceutical development. The advantages of these systems over the conventional methods include increase in drug entrapment and loading ability, incorporation of both hydrophilic and hydrophobic drugs, target delivery, use of various route of

\footnotetext{
* Address correspondence to this author at the Qmed Formulations Pvt. Ltd and Department of Pharmacy, Kathmandu University, Dhulikhel, Nepal; Email: gunjan_subedi@yahoo.com
} 
administration for delivery of the drug, increase in stability, reduction of dose and protection from biodegradation, ease in formulating the controlled release system, improved bioavailability etc. The future potential of the system in performing the delivery of the drugs, genes, DNA, RNA, plasmids, oligonucleotides etc. to the target site makes the study and investment in these kinds of drug delivery even more productive. The process of development of these systems includes the arrangement of polymeric chains to form a matrix inside which the drug may either be entrapped or dispersed or dissolved within the microspheres and nanospheres or adsorbed at their surface. Various methods such as solvent evaporation, solvent removal, polymerization, hot-melt encapsulation, coacervation, phase/wet inversion, spray drying, spray congealing, etc. can be adopted for the development of micro and nanospherical drug delivery systems. Amongst these, solvent evaporation method is one of the most common patented methods, which is widely studied for the preparation of the nano and microspherical systems. While designing these systems, it is very crucial to understand the various important formulation factors. Size is one of the most important factors that should be considered in the design and development of this system as size affects the interaction with the biological system, entry of the drug and drug release. Other important parameter is the loading and entrapment efficiency which in turn are related to the productivity of the pharmaceutical system.

\subsection{Microspheres}

Microspheres are the spherical particles of micrometer range (typically $1 \mu \mathrm{m}$ to $1000 \mu \mathrm{m}$ ) synthesized from natural and synthetic materials [1]. They are efficiently utilized in controlled delivery of many drugs. Wastage of drug due to low drug entrapment efficiency, repeatability and difficulty in scaling to large production facility are the major drawbacks of microspheres [2]. Thus, care should be taken while designing microspheres and design should be appropriate such that loading and entrapment efficiency of a particular drug can be enhanced and also drug wastage can be minimized. A sound knowledge about the effects of various variables in entrapment efficiency can help in designing the robust microsphere.

\subsubsection{Advantages}

1. Ease in injection due to spherical shape and small size.

2. Improves bioavailability and reduces the incidence or intensity of adverse effects.

3. Ease in controlling drug degradation and drug release [3].

\subsubsection{Limitations}

1. Cannot be subjected to physical pressure such as compression, chewing etc., as these may denature the morphology and thus the physical properties of microspheres.

2. Controlled release formulations generally contain a higher drug load and thus any loss in integrity of the release characteristics of the dosage form may lead to potential toxicity.

3. The release rate of the controlled release dosage form may vary due a variety of factors like food and the rate of transit through gut.

4. They cover a large surface area and thus, there are more chances of particle aggregation.

5. There are more chances of burst release owing to their extremely small size and large surface area.

\subsection{Nanospheres}

Nanospheres are small particles with a size range of 10 to $200 \mathrm{~nm}$. The hydrophobic surfaces of these particles are susceptible to opsonization and clearance by the reticulo endothelial system [4]. There are various kinds of nanospheres such as gelatin nanospheres, albumin nanospheres, modified starch nanospheres, propylene dextran nanospheres, polylactic acid nanospheres, magnetic nanospheres, immune nanospheres etc. Nanospheres can be prepared by various methods but the solvent evaporation is the most widely used. Nanospheres are extensively used for the targeted delivery systems [4].

\subsubsection{Advantages}

1. If attached to various types of ligands, they can be used for the size specific targeted delivery.

2. Suitable for administration through various routes of administration [5]. 
3. They can help to reduce the toxicity [6].

4. Can be used for developing various kinds of controlled drug delivery systems.

5. Due to their small spherical size, they can easily pass through the smallest capillary and thus help in the target delivery systems [7].

6. Rapid clearance from phagocytes can be avoided and thus help in prolonging the residence time in the blood stream.

\subsubsection{Drawback of Nanospheres Drug Delivery System}

1. Due to their small size, they cover a large surface area and thus there are more chances of particle aggregation.

2. Also, chances of burst release are more because of their extremely small size and large surface area.

\subsection{Preparation with Solvent Evaporation Method}

Solvent evaporation method is one of the most widely used methods due to its ease in the formulation process and also its suitability for various modifications for preparing micro and nanospherical systems with improved properties. It was first patented in 1979 by Vanderhoff et al. as a polymer emulsification process to obtain polymeric particles. This method finds its claims in several patents thereafter.

In this process, the polymer or micro or nano capsule coating agent is dispersed in a volatile solvent which is insoluble in liquid manufacturing vehicle phase. The core material or the drug to be encapsulated is then dissolved or dispersed in the coating polymer solution. Application of the stirring at certain speed causes the core material to get dispersed in the liquid manufacturing vehicle phase to obtain a desired size range of the microsphere. This technique forms an emulsion between polymer solution and continuous phase. With the application of heat or evaporation of the volatile solvent with stirring, the polymer shrinks around the core or forms the matrix microspheres as the core is also dissolved in the coating solution. This technique can incorporate both water soluble and insoluble core materials inside the matrix system [8]. The list of microspheres prepared with solvent evaporation method is given in Table 3.

\subsubsection{Advantages of the Method}

- Modifications in the solvent evaporation technique such as multiple emulsion technique can be devised to prevent degradation of the drug during encapsulation, to increase the drug loading and to improve the predictability of the drug release [9].

- Can be used for the entrapment and release modification of both water soluble and water insoluble drugs [10].

- Solvent evaporation method using the microfluidic droplet devices can be used to make particles that are up to three orders of magnitude of different sizes and to enable a fine control on the synthesis of drug carriers and can be integrated in a complex microfluidic system [11].

- Relatively simple and convenient method which can be used for protecting and targeting active agents, providing desired release profile, increasing efficacy and decreasing toxicity.

\subsection{Types of Solvent Evaporation Method}

\subsubsection{Single Emulsion System}

This is a moderately efficient method of entrapment of the drug as the problem of relatively poor encapsulation of water-soluble and moderately water soluble drugs are inherent. The list of nanoparticles prepared by solvent evaporation technique by single emulsion method is given in Table 1. In this method, the drug is dissolved in the solution of the polymer (aqueous system) and then is dispersed to the non-aqueous system (oil) by continuous agitation. Generally a shearing action is required to produce the emulsion droplets of small size than the conventional ones [12 15]. The second step involves cross-linking of the dispersed globule which is generally carried out by heat or by the means of cross linking agents such as glutaraldhyde or formaldehyde.

Table 1. List of nanoparticles prepared by solvent evaporation technique by single emulsion method.

\begin{tabular}{|l|l|l|l|}
\hline Patent No. & Drug & Polymer & References \\
\hline US20110212032A1 [2011]. & Iron oxide and Rhodamine & PLGA & {$[16]$} \\
\hline
\end{tabular}


(Table 1) contd.....

\begin{tabular}{|l|l|l|}
\hline Patent No. & Drug & Polymer \\
\hline US7728036B2 [2010]. & Nordihydroguaiaretic Acid [NDGA] & PLGA \\
\hline US20100159021A1 [2010]. & Resveratrol & Different polymers \\
\hline US20100331819A1 [2010]. & Texaphyrin, Porhyrin, Benzochlorin or Chlorophil & Different polymers \\
\hline US20060188543A1 [2006]. & Paclitaxel & [18] \\
\hline $\begin{array}{l}\text { US20060177416 A1 } \\
{[2006] .}\end{array}$ & Bupivacaine & PLG] \\
\hline WO2004112696A2 [2004]. & Nordihydroguaiaretic Acid & {$[20]$} \\
\hline
\end{tabular}

\subsubsection{Multiple Emulsion System}

This method is generally applied for the preparation of microspheres of water soluble drugs, protein, peptides and vaccine which are generally in the double or multiple emulsion form. The common research on nanoparticles that has been produced by double emulsion (solvent evaporation method) is given in Table 2 . The aqueous protein solution consisting of the drugs is dispersed in the lipophilic continuous phase. The primary emulsion thus formed is then homogenized and then added again to the aqueous solution of Poly Vinyl Alcohol (PVA), which results in the formation of a double emulsion. The solvent of the emulsion is then removed by the help of solvent evaporation or extraction. The emulsion is added with water to diffuse out the organic phase. After which the solid microspheres are obtained by centrifugation, filtration and washing with organic solvent to remove the traces of the oil from the surface [23]. Lyophilization can also be adopted to decrease the burst effect [24].

\section{Table 2. List of Nanoparticles produced by double emulsion method with solvent evaporation.}

\begin{tabular}{|c|c|c|c|}
\hline Drug & Polymer & Explanation & References \\
\hline Cisplatin & PBA & $\begin{array}{l}\text { Nanoparticles that enable the release of drug in small concentration in a controlled manner } \\
\text { were formulated which thus helped in controlling the nephron toxocity and ototoxicity. }\end{array}$ & {$[25]$} \\
\hline Aescin & PLGA & Effect of formulation parameters in zeta potential, entrapment and size was studied. & {$[26]$} \\
\hline Small interfering RNA & PLGA & Could encapsulate the small interfering RNA. & {$[27]$} \\
\hline 5-Flurouracil & PHBHHx & Small co-polymeric microspheres and nanospheres of spherical shape were obtained. & {$[28]$} \\
\hline Ritonavir/Lopinavir & PLGA & $\begin{array}{l}\text { Use of polaxomer and polyvinyl alcohol as a stabilizer and Methylene chloride as a solvent } \\
\text { to produce PLGA microsphere. }\end{array}$ & {$[29]$} \\
\hline Doxorubicin $\mathrm{HCl}$ & PLGA & Using polyvinyl alcohol as a stabilizer, small nanoparticles size were obtained. & {$[30]$} \\
\hline Bovine serum albumin & PLGA & Using polyvinyl alcohol as stabilizer, small nanoparticles size were obtained. & {$[31]$} \\
\hline Daunorubicin & PLGA/PLA & $\begin{array}{l}\text { Influence of various preparation parameters such as organic solvent, type of surfactant, } \\
\text { type of polymers and molecular weight was studied. }\end{array}$ & {$[32]$} \\
\hline Paclitaxel, caumarin & Chitosan & $\begin{array}{l}\text { Efficacy of chitosan coated PLGA nanoparticles as an efficient delivery system was } \\
\text { studied. }\end{array}$ & {$[33]$} \\
\hline Small interfering RNA & PLGA/PEI & $\begin{array}{l}\text { It was found that presence of PEI in PLGA nanoparticles increased siRNA encapsulation } \\
\text { by about } 2 \text {-fold and also improved release profile of siRNA. }\end{array}$ & {$[34]$} \\
\hline Brimonidine tartrate & $\begin{array}{l}\text { Eudragit RL } 100 / \\
\text { Eudragit RS100 }\end{array}$ & $\begin{array}{l}\text { Narrow size range of nanoparticles with improved drug loading could be obtained for } \\
\text { treating open angle glaucoma. }\end{array}$ & {$[35]$} \\
\hline
\end{tabular}

Table 3. Studies in Microspheres prepared by solvent evaporation technique.

\begin{tabular}{|l|l|l|l|}
\hline Drug & Polymer & Result and Inferences \\
\hline $\begin{array}{l}\text { rhVEGF (human vascular } \\
\text { endothelial growth factor) }\end{array}$ & Poly(lactic-co-glycolic acid); PLGA & $\begin{array}{l}\text { Sustained order release of VEGF was observed for 2 weeks. } \\
\text { Dynamic light scattering (DLS) 37] } \\
\text { microparticles of small variation in micro particle size } \\
(<2 \%) .\end{array}$ \\
\hline Etoposide & Poly ( $\varepsilon$-caprolactone) & $\begin{array}{l}\text { Sustained microsphere with narrow size distribution and } \\
\text { smooth surface. }\end{array}$ \\
\hline Aspirin & $\begin{array}{l}\text { Ethyl cellulose (EC), cellulose acetate } \\
\text { phthalate (CAP) and their mixture (1:1) }\end{array}$ & $\begin{array}{l}\text { Free flowing microspheres were observed. } \\
\text { EC showed slower release rate than CAP and mixture. }\end{array}$ \\
\hline Atenolol & Ethyl cellulose & $\begin{array}{l}\text { Effect of various factors on release and entrapment was } \\
\text { studied. }\end{array}$ \\
\hline [40] & $\begin{array}{l}\text { Good yield (87.5\%) and good entrapment efficiency } \\
(92.4 \%) \text { was observed. }\end{array}$ \\
\hline Telmisartan & Cellulose acetate & Hollow microsphere formation. \\
\hline
\end{tabular}


(Table 3) contd.....

\begin{tabular}{|c|c|c|c|}
\hline Drug & Polymer & Result and Inferences & References \\
\hline Nifedipine & Eudragit RL100 & $\begin{array}{l}\text { High drug-loading percent, successful retarding release } \\
\text { (over } 12 \text { hours) and spherical and smooth surface } \\
\text { morphology were obtained. }\end{array}$ & {$[43]$} \\
\hline Salbutamol sulphate & HPMC and Carbopol & $\begin{array}{l}\text { Good entrapment efficiency was observed }(68.3 \pm 0.01 \text { and } \\
94.9 \pm 0.02 \%) \text {. }\end{array}$ & {$[44]$} \\
\hline ValacyclovirHCl & Ethyl Cellulose & $\begin{array}{l}\text { Floating microsphere could be obtained which will have } \\
\text { high resident time in the upper part of GIT resulting in } \\
\text { improved absorption. }\end{array}$ & {$[45]$} \\
\hline Captopril & Eudragit S100, Ethyl Cellulose & A sustained release was obtained. & {$[46]$} \\
\hline Stavudine & Ethylcellulose, Dibutylpthalate & $\begin{array}{l}\text { Controlled release was obtained for a drug with very short } \\
\text { half life. }\end{array}$ & {$[47]$} \\
\hline Boswellic acid & HPMC, Ethylcellulose & Increased gastric retention & {$[48]$} \\
\hline Ranitidine & $\begin{array}{l}\text { HPMC K100, Xanthan gum, Eudragit } \\
\text { S100 }\end{array}$ & $\begin{array}{l}\text { Using acrylic and hydrophilic polymer, gastric residence } \\
\text { time can be increased. }\end{array}$ & {$[49]$} \\
\hline Rosiglitazone maleate & HPMC, Ethylcellulose] & $\begin{array}{l}\text { Decrease in gastric irritation, protection from gastric } \\
\text { degradation }\end{array}$ & {$[50]$} \\
\hline Cephalexin & Ethylcellulose & Sustained effect & {$[51]$} \\
\hline Famotidine & Acrylocoat S100, cellulose acetate & $\begin{array}{l}\text { The floating behavior, release rate and physical properties } \\
\text { are affected. }\end{array}$ & {$[52]$} \\
\hline Cefpodoximeproxetil & HPMC K100 M, Ethylcellulose & Sustained effect & {$[53]$} \\
\hline Rabeprazol sodium & HPMC, Methyl cellulose & $\begin{array}{l}\text { Improved short half life and prevention of degradation of } \\
\text { drug from lower part of stomach }\end{array}$ & {$[54]$} \\
\hline Clarithromycin & $\begin{array}{l}\text { HPMC 15M, K4M, } \\
\text { Ethylcellulose }\end{array}$ & Sustained effect & {$[55]$} \\
\hline Cimetidine & HPMC, Ethylcellulose & Sustained effect & {$[56]$} \\
\hline
\end{tabular}

\section{EFFECT OF FORMULATION VARIABLES ON DRUG RELEASE}

\subsection{Effect of Molecular Weight of Polymer on Drug Release}

It is a very clearly observed phenomenon that the release mechanism can easily be modulated by the weight of used polymer as higher molecular weight polymer shows slower release of the drugs [57]. It has been observed that at the same amount of polymer in the micro spherical system, the polymers of higher viscosity are difficult to dissolve. The main reason behind this phenomenon is the requirement of higher energy to pull the chain of polymers of higher viscosity from their matrix and formation of thicker gel layer after the hydration. The viscosity effect is mainly due to the differences in the molecular weight of the polymers. The following equation has been derived to explain the relation between the polymer molecular weight and disentanglement concentration [58]:

$\mathrm{Cp}$, dis $=2700 / \mathrm{MW}$

Where,

$\mathrm{MW}=$ molecular weight of the polymer,

$\mathrm{Cp}$, dis $=$ polymer disentanglement concentration .

The above relation shows that when the molecular weight of the polymer increases, the total porosity of the polymers decreases which causes prolonged release of drug from the microspherical system. Take for instance HPMC polymers such as HPMC k4M, HPMC k15M and HPMC K100M having molecular weight of 95, 120 and $250 \mathrm{kDa}$ in which HPMC K100M is seen to have a lower release rate than the others. This relationship also explains that at a higher MW, the polymer disentanglement concentration is very low and reaches a plateau [59]. Young and Nelson equation can be used to explain the sorption and desorption profile of different viscosity grades of HPMC polymers. These equations describe three locations of the sorbed moisture: monolayer adsorption, externally adsorbed moisture, and internally absorbed moisture. Increase in the polymer weight results in the reduction of amount of internal water absorption and increase in external adsorption. In the experiment on "Elucidating the moisture sorption and desorption profile of different viscosity grades of HPMC (K4M, K15M and K100M)", it was observed that the lowest value of internally absorbed moisture was obtained for HPMC K100M [60]. Since viscosity of the HPMC polymers is related to the molecular weight and has a large influence on the erosion rate of the matrix tablet, the erosion rate can be adjusted by the choice of HPMC polymer viscosity or by mixing polymers of different viscosity grades [61]. A higher molecular weight HPMC polymer thus has a higher water holding capacity and the matrices of such polymeric system are less 
prone to erosion [62].

Want et al. has explained that initial increase in the thickness of the matrix system (e.g microspheres and tablets) is higher for the higher molecular weight HPMC grades. With the increase in water sorption (hydration of the polymer chain), the disentanglement concentration is reached above which the polymers disentangle and detach from the gelled matrix resulting in the polymer erosion [63]. The effect of the molecular weight of the polymer has also been explained with the PLGA polymers with different molecular weights: PLGA 15000, PLGA 20,000 and PLGA 30,000 and it was found that with the increase in molecular weight, the loading capacity is increased because of presence of stronger barrier properties of polymers with high molecular weight [64]. The release of the drug from the microsphere is also the function of degradation of polymers. The release of the drug can be programmed into prolonged released systems by loading the drug into microspheres made of biodegradable aliphatic polyesters. For instance, the release of Gentamicin Sulphate was faster in PLHMGA than the PLGA polymers as degradation rate of PLHMGA is more rapid than PLGA $[65]$.

\subsection{Effect of Surfactant Concentration on Drug Release}

The incorporation of higher amount of surfactant is not usually a good idea for designing the controlled or sustained release microparticulate system because it has been observed that surfactant increases the rate and amount of drug release from the microparticulate system. The basic reason to explain this phenomenon is the increase in wettability and better solvent penetration inside the matrix system. Increase in surfactant concentration is also believed to increase the drugs deposited at the surface of those matrix microspherical systems [66].

The presence of the surfactants also affects the modification of encapsulated products such as insulin and gives rise to a sustained release profile from the matrices of microspheres. In a research, related to encapsulating bovine insulin with poly (lactide co-glycolide) using different concentrations of non-ionic surfactants like poloxamer 188, polysorbate 20 and sorbitan monooleate 80 , it was observed that during the period of sustained release, modification of insulin to a high-molecular weight product was observed and its amount was related to the surfactant used. Among all the surfactants used, polysorbate 80 at $3 \% \mathrm{w} / \mathrm{v}$ concentration was observed to have good insulin loading and slow drug release [67].

The HLB values of the emulsifiers have marked effect in defining the micromeretic properties, release and encapsulation of the drug in nano and microspherical systems. It is generally observed that emulsifiers with higher HLB were found to be more effective for the encapsulation of the drug and showed better control of drug release from the matrix system [68].

\subsection{Effect of Stirring Rate on Drug Release}

Various micro and nanospherical preparation methods require the use of stirrers. This is usually more popular in the solvent evaporation or the emulsion solvent evaporation technique. Stirring rate has been used to explain the average diameter of the microspherical system.

The sensitivity of polymer erosion to the degree of agitation can influence the polymer's ability to give reproducible and agitation-independent release in the complex hydrodynamic environment of the gastrointestinal tract compared to more rigid non-eroding matrix materials [69]. When the stirring rate is higher, it causes the formation of finer dispersion of the microparticles. When these microparticles are observed from SEM (Scanning Electron Microscope) photographs, the larger microspheres formed at lower stirring rate are seen to be porous than those formed at higher stirring rate. As the porosity of systems increases, the diffusion of the drug from the matrix system becomes easier [70]. On the another study, the influence of stirring speed on the release of drug from biodegradable matrix microsphere was studied which showed that by increasing speed from 400 to $1200 \mathrm{rpm}$, there was a marked effect on mean diameter of the microsphere which decreased from $251 \mu$ to $104 \mu$. The release rate of the drug was observed to be faster in the small size microsphere [71]. Particle size also had the influence on the release property of the drug from microspheres. This is also supported by the results of the research done by Pan Yan et al. where they found that particle size had an important influence on the release of insulin from microspheres. They found that larger particles released relatively less amount of insulin at the initial burst stage thus preventing initial burst which is considered as one of the main drawbacks of microsphere [72]. It has also been observed that drug release depends strongly on microsphere diameter of 10- $\mu \mathrm{m}$ and 20- $\mu \mathrm{m}$ particles exhibiting concave-downward release profiles while larger particles resulted in sigmoidal release profiles [73]. 


\subsection{Effect of Temperature Programming on Drug Release}

In all the methods of preparation of microsphere which involves evaporation of the volatile component, temperature has a very important role in defining the drug release. Generally, an abrupt increase in temperature during the manufacture or use of very high temperature causes the rapid expansion of methylene chloride from the body of the microsphere and causes the formation of hollow core and a thin permeable body [74]. It has been observed that the amount of continuous phase and the micro/nanoparticle: bulk fluid ratio affects the release behavior of drugs from the system. The solvent evaporation method is generally inconvenient for micro/nano spherical systems of water soluble drugs because there is tendency of drug loss from emulsified polymeric phase before solidification of polymer in microsphere [75]. Also, drug release is significantly faster in higher particle mass:bulk fluid volume ratio in case of non-porous and initially porous system which should be taken into account when defining the experimental conditions for drug release measurements from this type of advanced drug delivery systems [76].

\section{EFFECT OF FORMULATION VARIABLES ON DRUG ENTRAPMENT}

\subsection{Effect of Polymer Concentration on Drug Entrapment}

A higher molecular weight polymer has a greater degree of entanglement and thus will reduce the molecular diffusion area and permeation of the drug across the matrix gel. When the polymer concentration increases, there will be increase in the viscosity of the polymer gel and which thus results in longer diffusional path [77]. This causes a decrease in the diffusion coefficient of the drug and reduction in the release rate of the drug. In order to achieve a constant zero order or sustained release, the polymer should be hydrated fast to form a gel layer before the contents of the matrix tablet gets dissolved. For the higher viscosity gels, they become more resistant to dilution and erosion [78]. On the other hand, the polymer forming the loose network in the matrix is seen to decrease the release rate and encapsulation efficiency as the network allows the drug particles to leach out during the microsphere production [79]. It has been observed and widely accepted that an increase in the polymer concentration increases the entrapment of the drug inside the micro and nanospherical systems. The main reason for this phenomenon can be explained with the help of following points.

\subsubsection{Effect Due to Increase in Viscosity}

As explained earlier, high concentration of the polymer used to formulate the microspherical systems causes the increase in viscosity of the solution and delays the drug diffusion within the polymer droplets.

\subsubsection{Effect of Increase in Velocity of Precipitation}

When, the concentration of the polymers increases or the ratio of drug and polymer decreases, the polymers tend to precipitate faster on the surface of the dispersed phase and it can prevent drug diffusion across the phase boundary.

\subsubsection{Effect of Increase in Size}

With the increase in polymer concentration, the size of the microsphere increases. This causes a decrease in the surface area of the microspheres and decreased exposure to water. Thus, the drug loss due to diffusion from the gel layer also decreases. Decreasing the polymer concentration also leads to reduction in loading efficiency due to maximum drug: polymer ratio and small size of microspheres is obtained resulting in loss of drug from surface during washing of microspheres. In an experiment by Saravananet et al. where they formulated the floating microspheres of ranitidine hydrochloride with ethyl-cellulose as a polymer, they observed that increase in the polymer concentration increased the drug entrapment with maximum entrapment seen at a drug:polymer ratio 1:3 [80].

\subsection{Effect of Interaction Between Drug and Polymer on Drug Entrapment}

The interaction between drug and polymer may be hydrophilic or hydrophobic and may result in the drug release and entrapment from micro or nanospherical system. For hydrophobic interactions, the drug is best encapsulated in polymers containing with free carboxylic acid end groups. For hydrophobic interactions the encapsulation or the entrapment efficiency may be increased by relatively hydrophobic end capped polymers [81, 82]. It is also observed that the encapsulation of microsphere of tetanus toxoid formed with PLGA increased when formulated with hydroxylpropyl cyclodextrin (g-HPCD). It is supposed that the g-HPCD increased the interaction by involving amino acid side group of the toxoid into its cavity and simultaneously interacting with PLGA through Vander Waals and hydrogen bonding forces [83]. It is also observed that the complexation between the drug and the polymer may affect in the release of the 
drug from the matrix system. In a study of 23 drugs with different solubility and molecular weight, matrixed with HPMC and sodium carboxy methylcellulose, it was observed that very soluble and soluble drugs such as beta-blockers and soluble vitamins (thiamine hydrochloride) released more slowly in a matrix of HPMC and sodium carboxymethylcellulose due to complex formed between cationic drug and anionic polymer [84].

\subsection{Effect of Stirring Rate on Drug Entrapment}

Various experiments have been performed taking in consideration the observation of the stirring rate and its effect on the entrapment of the drug inside the matrix systems of microspheres. It has been observed that with the increase in the stirring rate, the mean particle size decreases and due to fast evaporation of the solvent from the matrix system during the manufacture, there is a formation of the hollow spheres. In the lower stirring rate such as $300 \mathrm{rpm}$, there is a formation of the solid and irregular type of microsphere. But as the rpm increases to 1000 or 1500 , various hollow spheres begin to form in the formulation process but the microspheres are spherical in nature. This property of formation of the hollow microspheres of spherical shape can be taken as an attribute for the entrapment of the drug to transfer inside the narrow capillary space. In an experiment of formation of the microspheres of Diltiazem $\mathrm{HCl}$ using Eudragit RS100 and Eudragit RL 100 in which the stirring speed had been applied between 300 to 1000 rpm, solid and irregular microparticles were seen at a lower stirring rate while at $600 \mathrm{rpm}$ particles size and drug entrapment efficiency were $82 \%$ and $210 \mu \mathrm{m}$, respectively, and at $1000 \mathrm{rpm}$ spherical shape of microspheres was observed but particles coalesced to beaker wall and also decrease with decreased particle size [85]. Increase in stirring speed is thus little difficult to obtain the small microparticles owing to the loss of formulation by adhering on the walls of manufacturing vessels. Similar results were obtained in the research conducted by S. Jose et al. in the study of colon specific chitosan microspheres for chronotherapy of chronic stable angina where they observed that increasing the stirring rate from 1000 to $2000 \mathrm{rpm}$, decreases the entrapment efficiency from $89 \%$ to $86.5 \%$ [86]. In the experiment of preparation of thermoresponsive hydrogel of $\mathrm{N}$-isopropylacrylamide, it was observed that the size distribution could readily be programmed by altering the stirring rate and changing the concentration of lecithin in the formulation [87].

\subsection{Effect of Surfactant Concentration on Drug Entrapment}

It has been observed that surfactant affects both the drug release and drug entrapment in the microspherical system. Increase in surfactant concentration leads to decrease in encapsulation efficiency of microspheres due to the fact that increase in surfactant concentration leads to stabilization of small droplets and results in smaller microspheres. Loss of drug from surface of small microspheres is more than that of larger microspheres during washing [88]. In one study of variability of PLGA nanoparticles quality by Placket- Burman design, it was observed that the higher concentration of the emulsifier increased the partition of drug from internal to external phase due to increased solubility of the drug in the external phase [89]. Statistical analysis of the results of the study showed that the increase in emulsifier concentration caused a decrease in the entrapment efficiency.

\subsection{Effect of Cross-Linking Agents on Drug Entrapment}

Benergee et al. observed that entrapment can be increased in interprenating polymer network (IPN) based formulation by the incorporation of higher amount of cross linking agents like gluteraldehyde, therefore, for the slightly soluble drugs, incorporation of optimized amount of cross-linker can improve the entrapment [90]. This has also been observed in the case of mucoadhesive microspheres. Patel et al. investigated in the effect of cross linker on drugloading efficiency of glipizide mucoadhesive microspheres where a significant effect on mucoadhesion and drug entrapment efficiency of microspheres was observed. This could be explained as when the amount of glutaraldehyde increases, it tends to favor the cross-linking and consequently forming spherical free-flowing microspheres with an increase in drug loading efficiency [91].

\subsection{Effect of Temperature on Drug Entrapment}

Temperature has the significant role in affecting the morphology, entrapment and release rate of the drug from the microspherical systems. It has been observed that at higher temperature, the microspheres have hollow core and porous wall owing to the fact that the volatile components such as methylene chloride used in the formulation of the microspheres evaporate rapidly at a higher temperature. It has also been observed that the core size and wall thickness are depended on the temperature ramp. A rapid rise in temperature results in a thin wall and a large hollow core, whereas a stepwise temperature rise $\left(15\right.$ to 25 , then to $\left.40^{\circ} \mathrm{C}\right)$ results in a reduced core size [92]. 


\section{EFFECTS OF FORMULATION VARIABLES ON MICROSPHERE SIZE}

\subsection{Effect of Polymer Concentration on Microsphere Size}

It is widely observed phenomenon that the particle size of the microspheres increases as the ratio of polymer increases in the microspherical system because of increase in the viscosity of the polymer which results in formation of larger emulsion droplets and thus consecutively larger size of the microspheres. The explanations were well observed in an experiment by Patel et al. where the particle size of aspirin loaded microspheres was analyzed by optical microscopy. The average particle size of microspheres was found to be in the range of 328 to $990 \mu \mathrm{m}$. The polymer solution of increasing concentration showed greater size in SEM [93]. The polymer concentration has also been observed to have effect on the size of the nanospheres. Lung-Hsin Hung et al. studied a new method for nanosphere synthesis by droplet microfluidic solvent evaporation technique where they observed that increase in initial PLGA concentration increased the diameter of the particles and also increased the particle volume. An increase in the concentration of PLGA from $0.5 \%$ to $5 \%$ increases the volume by 20 folds from 0.52 to 9.2 pl. This concludes that on increasing the concentration of PLGA, it decreases the density and hence results in larger matrix size and cargo capacity [94].

\subsection{Effect of Surfactants on the Microsphere Size}

\subsubsection{Effect of Surfactants of Different HLB Values on the Size of Microspheres}

The particle size of the microsphere increases with the increase in the HLB value of the surfactant being used. Microspheres prepared using surfactants of higher HLB value are larger in size and competitively have a higher entrapment efficiency which is due to the fact that the entrapment efficiency increases with the increase in the microsphere size. Similar results were obtained in an experiment where the effect of surfactants like span 80 and span 20 on particle sizes and entrapment efficiency of tramadol loaded PCL microspheres were studied. The results demonstrated that the microspheres prepared using span 80 were smaller than that of span 20. And the mixture of surfactants showed further smaller microspheres [95].

\subsubsection{Effect of Surfactant Concentration on the Size of Microspheres}

It has been observed that increase in concentration of the surfactant used to manufacture the microspheres causes decrease in the size of the microsphere owing to the fact that increase in concentration of the surfactant causes decrease in the interfacial energy between the two droplets and the presence of emulsifying agent in the cross linking medium, allowing the stabilization of the preformed microspheres to maintain their size until completion of the cross linking reaction. Similar results were obtained in the experiments of Patel et al. in preparation and evaluation of ethyl cellulose microspheres by emulsification-solvent evaporation method where increase in concentration of the emulsifying agent caused decrease in the particle size of the microspherical system [96].

\subsection{Effect of Stirring Rate on the Microsphere Size}

Stirring speed also affects the percentage yield and mean microparticle size because of the turbulence developed. In higher rate of the stirrer $(1500 \mathrm{rpm})$, there was the production of froth and adhesion in the walls of the container which consequently decrease the mean particle size of the microsphere. An optimum spherical shape and state free from aggregation was obtained to the stirring speed of $1000 \mathrm{rpm}$. An increase in particle size at low stirring speed (500 rpm) can be explained on the basis of tendency of the globules to aggregate and coalesce [97].

Target drug release with the help of encapsulation techniques such as microspheres is an important future directive in the formulation works. Microspheres thus have to maintain an acceptable size for the drug permeation and targeting to the desired location. The explanations are also supported by experiment by Gülen Melike Demir et al. where on increasing the stirring rate from 8,000 to $20,000 \mathrm{rpm}$, the particle size decreased from $72.54 \mu \mathrm{m}$ to $13.67 \mu \mathrm{m}$ and also increased the zeta potential 0.135 to $0.245 \mathrm{Mv}$ [98].

\subsection{Effect of Viscosity of the Dispersed and Continuous Phase on the Microsphere Size}

It has been observed that the viscosity of the dispersed and the continuous phase greatly affects the microsphere size. In an experiment, microspheres were prepared using a hydrocarbon-perfluorocarbon solvent extraction process. It was observed that smaller microspheres were produced at the same mixing intensity when the viscosity of the dispersed phase was decreased. Increased continuous phase viscosity reduced the coalescence of the droplets and hence smaller 
microspheres were produced. The mean microsphere size was first found to decrease as the volume ratio of the dispersed phase to the continuous phase increased but upon further increase, the mean microsphere size was found to increase [99].

\section{CONCLUSION}

Micro and nanospherical formulations find their increasing role in drug delivery, storage and entrapment system in the recent times. Many approaches have been devised for the preparation of the micro and nanospheres among which solvent evaporation method is widely used due to its ease of formulation and process control. However, a thorough knowledge of various process engineering factors such as effects of polymer type, weight, viscosity, hydrophilicity, concentration, polymer ratio, stirring speed, emulsifier concentration, concentration of cross-linking agents, type of solvent used for the formulation, rate of addition of the solvent etc. are of the essence in the design of a robust micro and nanospherical system as these factors affect the yield, morphology, release and entrapment of the drug inside the system.

\section{ABBREVIATIONS}

$\begin{array}{lll}\text { CAP } & = & \text { Cellulose Acetate Phthalate. } \\ \text { EC } & = & \text { Ethyl Cellulose. } \\ \text { HPCD } & = & \text { Hydroxylpropylcyclodextrin. } \\ \text { HPMC } & = & \text { Hydroxy Propyl Methyl Cellulose. } \\ \text { PLGA } & = & \text { Poly (lactic-co-glycolic acid) } . \\ \text { SEM } & = & \text { Scanning Electron Microscope. }\end{array}$

\section{CONFLICT OF INTEREST}

The authors confirm that this article content has no conflict of interest.

\section{ACKNOWLEDGEMENTS}

The authors are very thankful to the entire team of Kathmandu University especially Ms. Uma Bhasima and Mr. Basanta Dhodary of University of Konstanz for providing kind support in the completion of this manuscript. The review works bears no financial support from commercial sources.

\section{REFERENCES}

[1] Kataria S, Akanksha M, Premjeet S, Bilandi A, Kapoor B. Microsphere: a review. Int J Res Pharm Chem 2011; 4: 1184-97.

[2] Dhakar R. Variables influencing the drug entrapment efficiency of microspheres: A pharmaceutical review. Pharm Lett 2010; 2(5): 102-16.

[3] Subedi G, Maharjan R. Influence of different hydroxypropyl methylcellulose polymers in defining the micromeretic properties, erosion, drug entrapment and release from microspheres. Int J Pharm Pharm sci 2015; 5(1): 295-316.

[4] Singh A, Garg G, Sharma PK. Nanospheres: a novel approach for targeted drug delivery system. Int J Pharm Sci Rev Res 2010; 5: 84-8.

[5] Mohan VJ, Chen Y. Nanoparticles: a review. Trop J Pharm Res 2006; 5: 561-73.

[6] Zhang Q, Shen Z, Nagai T. Prolonged hypoglycemic effect of insulin-loaded polybutylcyanoacrylate nanoparticles after pulmonary administration to normal rats. Int J Pharm 2001; 218(1-2): 75-80. [http://dx.doi.org/10.1016/S0378-5173(01)00614-7] [PMID: 11337151]

[7] Illum L. Nanoparticulate systems for nasal delivery of drugs: a real improvement over simple systems? J Pharm Sci 2007; 96(3): 473-83. [http://dx.doi.org/10.1002/jps.20718] [PMID: 17117404]

[8] Parmar H, Sunil B, Nayan G, Bhushan R, Sunil P. Different methods of formulation and evaluation of mucoadhesive microsphere. Int J Appl Biol Pharm Technol 2010; 3: 1157-67.

[9] Subedi G, Shrestha AK, Shakya S. Formulation and in-vitro evaluation of controlled release tramadol hydrochloride microspheres and study of the factors affecting drug entrapment efficiency and drug release using central composite design. J Int Res Med Pharm Sci 2015; 8(3): 129-39.

[10] Kshirsagar DS, Saudagar RB. Microsphere: a review. Res J Top Cosmet Sci 2017; 7(1): 27-37.

[11] Marre S, Jensen KF. Synthesis of micro and nanostructures in microfluidic systems. Chem Soc Rev 2010; 39(3): 1183-202.

[12] Sudhamani T, Noveen Kumar RK, Ravi Kumar VR, Revathi R, Ganesan V. Preparation and evaluation of ethyl cellulose microspheres of ibuprofen for sustained drug delivery. IJPRD 2010; 8: 119-25. 
[13] Maji R, Ray S, Das B, Nayak AK. Ethyl cellulose microparticles containing metformin HCl by emulsification-solvent evaporation technique: Effect of formulation variables. ISRN Polym Sci 2012; 10: 1-6.

[14] Maharjan R, Subedi G. Formulation and evaluation of floating in-situ gel of ranitidine using natural polymers. Int J Pharm Pharm Sci 2014; 6(10): 205-9.

[15] Singh MN, Hemant KS, Ram M, Shivakumar HG. Microencapsulation: A promising technique for controlled drug delivery. Res Pharm Sci 2010; 5(2): 65-77. [PMID: 21589795]

[16] Chung BH, Yong T, Jung H. Polymer particles for NIR/MR bimodal molecular imaging and method for preparing the same. Patent US $12 / 672,185,2008$

[17] Huang RC, Park R, Chang CC, et al. Methods for delivery of catecholic butanes for treatment of tumors. Patent US 7728036, 2010.

[18] Davis P, Davis FB, Mousa SA, Hung YL. Small molecule ligands of the integrin RGD recognition site and methods of use. Patent US $12 / 644,493,2009$

[19] Hossainy S, Dariush D, Mikael T, John S, Yuet MK, Jinping W. Drug delivery system and method of treatment of vascular diseases using photodynamic therapy. Patent US 12/491,063, 2009.

[20] Feng Si-Shen. Nanoparticle coating for drug delivery. US Patent 11/342,662, 2006.

[21] William TG, Li H, Gomurashvili ZD, Katsarava R. Polymer particle delivery compositions and methods of use. Patent US 13/477,832, 2012.

[22] Heller J, Neil F, Collins AT. Methods and compositions for delivery of catecholic butanes for treatment of diseases. Patent US WO2004112696A2, 2004.

[23] Jie Li. Fabrication of ABS/PC alloy hollow microspheres via water/oil/water emulsion solvent evaporation. Mater Lett 2011; 65(17): 2696-9.

[24] Mahdavi H, Hamid M, Hamed H, et al. The effect of process parameters on the size and morphology of poly (D, L-lactide-co-glycolide) micro/nanoparticles prepared by oil in oil emulsion/solvent evaporation technique. J Appl Polym Sci 2010; 1: 528-34.

[25] Khoee S, Ahmad S, Fatemeh A. Physico-chemical properties investigation of cisplatin loaded polybutyladipate (PBA) nanoparticles prepared by w/o/w. Mater Sci Eng: C 2012; 5: 1078-86.

[26] Van deVen H, Vermeersch M, Matheeussen A, et al. PLGA nanoparticles loaded with the antileishmanialsaponin $\beta$-aescin: Factor influence study and in vitro efficacy evaluation. Int J Pharm 2011; 420: 122-32.

[27] Cun D, Jensen DK, Maltesen MJ, et al. High loading efficiency and sustained release of siRNA encapsulated in PLGA nanoparticles: quality by design optimization and characterization. Eur J Pharm Biopharm 2011; 77(1): 26-35. [http://dx.doi.org/10.1016/j.ejpb.2010.11.008] [PMID: 21093589]

[28] Lu X-Y, Zhang Y, Wang L. Preparation and in vitro drug-release behavior of 5-fluorouracil-loaded poly(hydroxybutyratecohydroxyhexanoate) nanoparticles and microparticles. J Appl Polym Sci 2010; 116(5): 2944-50.

[29] Destache CJ. Nanoparticles and methods of use. Patent US 20110236437, 2011.

[30] Kreuter J, Svetlana G, Olga M, Alexander K. Polylactide nanoparticles. Patent US 8003128, 2011.

[31] Feczko T, Toth J, Dosa G, Gyenis J. Influence of process conditions on the mean size of PLGA nanoparticles. Chem Eng Process: Process Intensific 2011; 8: 846-53

[32] Liu J, Qiu Z, Wang S, Zhou L, Zhang S. A modified double-emulsion method for the preparation of daunorubicin-loaded polymeric nanoparticle with enhanced in vitro anti-tumor activity. Biomed Mater 2010; 5(6): 065002. [http://dx.doi.org/10.1088/1748-6041/5/6/065002] [PMID: 20924138]

[33] Kim B-S, Kim C-S, Lee K-M. The intracellular uptake ability of chitosan-coated Poly (D,L-lactide-co-glycolide) nanoparticles. Arch Pharm Res 2008; 31(8): 1050-4. [http://dx.doi.org/10.1007/s12272-001-1267-5] [PMID: 18787796]

[34] Patil Y, Panyam J. Polymeric nanoparticles for siRNA delivery and gene silencing. Int J Pharm 2009; 367(1-2): 195-203. [http://dx.doi.org/10.1016/j.ijpharm.2008.09.039] [PMID: 18940242]

[35] Bhagav P, Upadhyay H, Chandran S. Brimonidine tartrate-eudragit long-acting nanoparticles: formulation, optimization, in vitro and in vivo evaluation. AAPS PharmSciTech 2011; 12(4): 1087-101. [http://dx.doi.org/10.1208/s12249-011-9675-1] [PMID: 21879393]

[36] Karal-Yilmaz O, Serhatli M, Baysal K, Baysal BM. Preparation and in vitro characterization of vascular endothelial growth factor (VEGF)loaded poly(D,L-lactic-co-glycolic acid) microspheres using a double emulsion/solvent evaporation technique. J Microencapsul 2011; 28(1): 46-54. [http://dx.doi.org/10.3109/02652048.2010.523795] [PMID: 21171816]

[37] Hung LH, Teh SY, Jester J, Lee AP. PLGA micro/nanosphere synthesis by droplet microfluidic solvent evaporation and extraction approaches. Lab Chip 2010; 10(14): 1820-5. [http://dx.doi.org/10.1039/c002866e] [PMID: 20467687]

[38] Maghara DD, Nandhakumar S, Vankayalu DS, Suresh C. Preparation of poly (epsilon-caprolactone) microspheres containing etoposide by solvent evaporation method. Asian J Pharm Sci 2010; 5: 114-22. 
[39] Dash V, Mishra SK, Singh M, Goyal AK, Rath G. Release kinetic studies of aspirin microcapsules from ethyl cellulose, cellulose acetate phthalate and their mixtures by emulsion solvent evaporation method. Sci Pharm 2010; 78(1): 93-101. [http://dx.doi.org/10.3797/scipharm.0908-09] [PMID: 21179372]

[40] Yadava N, Mohiteb DD, Pawarb KR, Pawarb UR, Bhiseb SB, Sandeb TA. Synthesis and characterization of sustained release atenolol microspheres by solvent evaporation technique. J Pharm Sci Tech 2011; 3(2): 559-62.

[41] Sahoo SK, Barik S, Dehury G, et al. Evaluation of controlled release theophylline microspheres prepared with cellulose acetate using solvent evaporation method. Trop J Pharm Res 2011; 10(2): 195-201.

[42] Bansode SD, Kasture VS, Pawar SS, Kasture SB. Formulation and evaluation of telmisartan microspheres by emulsion solvent evaporation technique. J Appl Pharm 2012; 2: 113-6.

[43] Solmaz D, Reza A, Mohammadreza A, Ramin K. Formulation optimization of nifedipine containing microspheres using factorial design. Afr J Pharm Pharmacol 2010; 6: 346-54.

[44] Prasanth VV, Chakraborty A, Mathew ST, Mathappan R, Kamalakkannan V. Formulation and evaluation of salbutamol sulphate microspheres by solvent evaporation method. J Appl Pharm Sci 2011; 1(5): 133.

[45] Goswami N, Joshi G, Sawant K. Floating microspheres of valacyclovir $\mathrm{HCl}$ : Formulation, optimization, characterization, in vitro and in vivo floatability studies. J Pharm Bioallied Sci 2012; 4(Suppl. 1): S8-9. [http://dx.doi.org/10.4103/0975-7406.94118] [PMID: 23066217]

[46] Gadad A, Naval C, Patel K, Dandagi P, Mastiholimath V. Formulation and evaluation of floating microspheres of captopril for prolonged gastric residence time. Inventi Rapid - NDDS 2011; 3: 34.

[47] Tanvi R, Diwan A. Novel polymeric combinations for gastroretentive microspheres of stavudine. Int J Drug Dev Res 2011; 3: 211-6.

[48] Suresh F, Jha SK, Manvendra SK, Rohit G, Ankit V. Formulation and evaluation of floating microspheres of boswellic acid. Int J Pharm Tech Res 2011; 1: 76-81.

[49] Darapu BN, Sundaramoorthy K, Vetrichelvan T. Formulation and in-vitro evaluation of gastroretentive floating microspheres of ranitidine hydrochloride. Res J Pharm Dosage Form Technol 2011; 1: 24.

[50] Kavitha K, Mehaboob Y, Ashvini V, Sandeep DS. Formulation and in vitro evaluation of floating microbaloons of rosiglitazone maleate. Res J Pharm Biol Chem Sci 2011; 2: 833-42.

[51] Vasava K, Rajesh KS, Jha LL. Formulation and evaluation of floating microspheres of Cephalexin. Int J Pharm Sci Rev Res 2011; 2: 69-75.

[52] Bandana S, Jovita K, Manisha P. Formulation and evaluation of floating microspheres of famotidine. Metabolism 2010; 3: 4.

[53] Pande AV, Vaidya PD, Arora A, Dhoka MV. In vitro and in vivo evaluation of ethyl cellulose based floating microspheres of cefpodoximeproxetil. Int J Pharm Biomed 2010; 4: 122-8.

[54] Senthilkumar SK, Jaykar B, Kavimani S. Formulation, characterization and in vitro evaluation of floating microsphere containing rabeprazole sodium. J Innovative Trends Pharm Sci 2010; 1(6): 274-82.

[55] Chudiwal PD, Pawar PL, Nagaras MA, et al. Statistical evaluation and optimization of influence of viscosity and content of polymer on floating microspheres of clarithromycin. Int J Pharm Tech Res 2009; 4: 1366-72.

[56] Srivastava AK, Ridhurkar DN, Wadhwa S. Floating microspheres of cimetidine: formulation, characterization and in vitro evaluation. Acta Pharm 2005; 55(3): 277-85. [PMID: 16375838]

[57] Kumari A, Yadav SK, Yadav SC. Biodegradable polymeric nanoparticles based drug delivery systems. Colloids Surf B Biointerfaces 2010; 75(1): 1-18. [http://dx.doi.org/10.1016/j.colsurfb.2009.09.001] [PMID: 19782542]

[58] Heng PW, Chan LW, Easterbrook MG, Li X. Investigation of the influence of mean HPMC particle size and number of polymer particles on the release of aspirin from swellable hydrophilic matrix tablets. J Control Release 2001; 76(1-2): 39-49. [http://dx.doi.org/10.1016/S0168-3659(01)00410-2] [PMID: 11532311]

[59] Rahman Md, Sumon R, Sreedam CD, et al. Evaluation of various grades of hydroxypropyl methylcellulose matrix systems as oral sustained release drug delivery systems. J Pharm Sci Res 2011; 3: 930-8.

[60] Nokhodchi A, Ford JL, Rubinstein MH. Studies on the interaction between water and (hydroxypropyl)methylcellulose. J Pharm Sci 1997; 86(5): 608-15.

[http://dx.doi.org/10.1021/js960279a] [PMID: 9145387]

[61] Tahara K, Ken Y, Toshiaki N. Overall mechanism behind matrix sustained release (SR) tablets prepared with hydroxypropyl methylcellulose 2910. J Control Release 1995; 31: 59-66. [http://dx.doi.org/10.1016/0168-3659(95)00021-Y]

[62] Kavanagh N, Corrigan OI. Swelling and erosion properties of hydroxypropylmethylcellulose (Hypromellose) matrices--influence of agitation rate and dissolution medium composition. Int J Pharm 2004; 279(1-2): 141-52. [http://dx.doi.org/10.1016/j.ijpharm.2004.04.016] [PMID: 15234802]

[63] Abrahamsson B, Alpsten M, Bake B, Larsson A, Sjögren J. In vitro and in vivo erosion of two different hydrophilic gel matrix tablets. Eur J Pharm Biopharm 1998; 46(1): 69-75. 
[http://dx.doi.org/10.1016/S0939-6411(98)00002-2] [PMID: 9700024]

[64] Fu X, Ping Q, Gao Y. Effects of formulation factors on encapsulation efficiency and release behaviour in vitro of huperzine A-PLGA microspheres. J Microencapsul 2005; 7: 705-14.

[65] Chaisri W, Ghassemi AH, Hennink WE, Okonogi S. Enhanced gentamicin loading and release of PLGA and PLHMGA microspheres by varying the formulation parameters. Colloids Surf B Biointerfaces 2011; 84(2): 508-14. [http://dx.doi.org/10.1016/j.colsurfb.2011.02.006] [PMID: 21353499]

[66] Pachuau L, Bhaskar M. A study on the effects of different surfactants on ethylcellulose microspheres. Int J Pharm Tech 2009; 4: 966-71.

[67] Rosa GD, Iommelli R, La Rotonda MI, Miro A, Quaglia F. Influence of the co-encapsulation of different non-ionic surfactants on the properties of PLGA insulin-loaded microspheres. J Control Release 2000; 69(2): 283-95. [http://dx.doi.org/10.1016/S0168-3659(00)00315-1] [PMID: 11064135]

[68] Ranjha NM, Khan H, Naseem S. Encapsulation and characterization of controlled release flurbiprofen loaded microspheres using beeswax as an encapsulating agent. J Mater Sci Mater Med 2010; 21(5): 1621-30. [http://dx.doi.org/10.1007/s10856-010-4034-4] [PMID: 20217193]

[69] Kavanagh N, Corrigan OI. Swelling and erosion properties of hydroxypropylmethylcellulose (Hypromellose) matrices--influence of agitation rate and dissolution medium composition. Int J Pharm 2004; 279(1-2): 141-52.

[http://dx.doi.org/10.1016/j.ijpharm.2004.04.016] [PMID: 15234802]

[70] Mateovic T, Kriznar B, Bogataj M, Mrhar A. The influence of stirring rate on biopharmaceutical properties of Eudragit RS microspheres. J Microencapsul 2002; 19(1): 29-36. [http://dx.doi.org/10.1080/02652040010055289] [PMID: 11811756]

[71] Dinarvand R, Moghadam SH, Mohammadyari-Fard L, Atyabi F. Preparation of biodegradable microspheres and matrix devices containing naltrexone. AAPS PharmSciTech 2003; 4(3): E34. [http://dx.doi.org/10.1208/pt040334] [PMID: 14621966]

[72] Pan Y, Zheng JM, Zhao HY, Li YJ, Xu H, Wei G. Relationship between drug effects and particle size of insulin-loaded bioadhesive microspheres. Acta Pharmacol Sin 2002; 23(11): 1051-6. [PMID: 12421485]

[73] Berkland C, King M, Cox A, Kim K, Pack DW. Precise control of PLG microsphere size provides enhanced control of drug release rate. J Control Release 2002; 82(1): 137-47. [http://dx.doi.org/10.1016/S0168-3659(02)00136-0] [PMID: 12106984]

[74] Dhakar RC, Maurya SD, Sagar PS, Bhagat S, Prajapati SK, Jain CP. Variables influencing the drug entrapment efficiency of microspheres: A pharmaceutical review. Pharm Lett 2010; 5: 102-16.

[75] Niwa TH, Takeuchi H, Hino T, Kunou N, Kawashima Y. Preparations of biodegradable nanospheres of water-soluble and insoluble drugs with D, L-lactide/glycolide copolymer by a novel spontaneous emulsification solvent diffusion method, and the drug release behavior. $\mathrm{J}$ Control Release 1993; 25: 89-98. [http://dx.doi.org/10.1016/0168-3659(93)90097-O]

[76] Klose D, Siepmann F, Willart JF, Descamps M, Siepmann J. Drug release from PLGA-based microparticles: effects of the “microparticle:bulk fluid" ratio. Int J Pharm 2010; 383(1-2): 123-31. [http://dx.doi.org/10.1016/j.ijpharm.2009.09.012] [PMID: 19748558]

[77] Akbari J, Reza E, Majid S, Massoud S. Influence of hydroxypropyl methylcellulose molecular weight grade on water uptake, erosion and drug release properties of diclofenac sodium matrix tablets. Trop J Pharm Res 2011; 5: 535-41.

[78] Sinha RD, Rohera BD. Comparative evaluation of rate of hydration and matrix erosion of HEC and HPC and study of drug release from their matrices. Eur J Pharm Sci 2002; 16(3): 193-9.

[http://dx.doi.org/10.1016/S0928-0987(02)00103-3] [PMID: 12128174]

[79] Banerjee. Interpenetrating polymer network (IPN) hydrogel microspheres for oral controlled release application. Int J Biol Macromol 2012; 50: 198-206.

[80] Saravanan M, Anupama B. Development and evaluation of ethylcellulose floating microspheres loaded with ranitidine hydrochloride by novel solvent evaporation-matrix erosion method. Carbohyds Polym 2011; 3: 592-8. [http://dx.doi.org/10.1016/j.carbpol.2011.03.020]

[81] Park TG, Yong Lee H, Sung Nam Y. A new preparation method for protein loaded poly(D, L-lactic-co-glycolic acid) microspheres and protein release mechanism study. J Control Release 1998; 55(2-3): 181-91. [http://dx.doi.org/10.1016/S0168-3659(98)00050-9] [PMID: 9795050]

[82] Crotto G, Park TG. Stability and release of bovine serum albumin encapsulated within PLGA microencapsulation. J Control Release 1997; 44: 123-34. [http://dx.doi.org/10.1016/S0168-3659(96)01511-8]

[83] Viswanathan NB, Thomas PA, Pandit JK, Kulkarni MG, Mashelkar RA. Preparation of non-porous microspheres with high entrapment efficiency of proteins by a (water-in-oil)-in-oil emulsion technique. J Control Release 1999; 58(1): 9-20. [http://dx.doi.org/10.1016/S0168-3659(98)00140-0] [PMID: 10021485] 
[84] Rao KV, Padmalatha D, Buri P. Influence of molecular size and water solubility of the solute on its release from swelling and erosion controlled polymeric matrices. J Control Release 1990; 2: 133-41. [http://dx.doi.org/10.1016/0168-3659(90)90089-C]

[85] Rathod UC, Patel AK, Dushyant AS. Statistical evaluation and optimization of influence of stirring speed and polymer concentration on hollow microspheres of diltiazem HCl. D Pharm Lett 2012; 5: 102-6.

[86] Jose S, Prema MT, Chacko AJ, Thomas AC, Souto EB. Colon specific chitosan microspheres for chronotherapy of chronic stable angina. Colloids Surf B Biointerfaces 2011; 83(2): 277-83. [http://dx.doi.org/10.1016/j.colsurfb.2010.11.033] [PMID: 21194900]

[87] D'Emanuele A, Dinarvand R. Preparation, characterization, and drug release from thermoresponsive microspheres. Int J Pharm 1995; 2: $237-42$.

[88] Thakkar H, Rakesh KS, Anil KM, Krishna C, Rayasa RM. Albumin microspheres as carriers for the antiarthritic drug celecoxib. AAPS PharmSciTech 2005; 6(1): E65-73. [http://dx.doi.org/10.1208/pt060112]

[89] Rahman Z, Zidan AS, Habib MJ, Khan MA. Understanding the quality of protein loaded PLGA nanoparticles variability by Plackett-Burman design. Int J Pharm 2010; 389(1-2): 186-94.

[http://dx.doi.org/10.1016/j.ijpharm.2009.12.040] [PMID: 20038446]

[90] Banerjee S, Gaurav C, Dilipkumar P, Ashoke G, Animesh G, Santanu K. Investigation on crosslinking density for development of novel interpenetrating polymer network (IPN) based formulation. J Sci Indust Res 2010; 10: 777-84.

[91] Patel JK, Patel RP, Avani FA, Madhabhai MP. Formulation and evaluation of mucoadhesive glipizide microspheres. AAPS PharmSciTech 2005; 6(1): E49-55.

[http://dx.doi.org/10.1208/pt060110]

[92] Dhakar RC, Maurya SD, Sagar BPS, Bhagat S, Prajapati SK, Jain CP. Variables influencing the drug entrapment efficiency of microspheres: A pharmaceutical review. Pharm Lett 2010; 2(5): 102-6.

[93] Patel B, Modi V, Patel K, Patel M. Preparation and evaluation of ethyl cellulose microspheres prepared by emulsification-solvent evaporation method. Int J Res Manage Pharm 2012; 1(1): 82-90.

[94] Lung-Hsin H, Shia-Yen T, James J, Lee AP. PLGA micro/nanosphere synthesis by droplet microfluidic solvent evaporation and extraction approaches. Lab Chip 2010; 10(14): 1820-5.

[95] Bhanupriya B. Preparation and charactrisation of tramadol microspheres for post-operative pain. Int J Pharm Biol Arch 2011; 2(3): 938-44.

[96] Maji R, Ray S, Das B, Nayak AK. Ethyl cellulose microparticles containing metformin HCl by emulsification-solvent evaporation technique: Effect of formulation variables. ISRN Polym Sci 2012; 10: 1-6.

[97] Jelvehgari M, Nokhodchi A, Rezapour M, Valizadeh H. Effect of formulation and processing variables on the characteristics of tolmetin microspheres prepared by double emulsion solvent diffusion method. Indian J Pharm Sci 2010; 72(1): $72-8$. [http://dx.doi.org/10.4103/0250-474X.62251] [PMID: 20582193]

[98] Gulen MD, Alptug K, Zelihagul DG. Stirring speed effects of physical characteristics of theophylline microsphere. In: Proceedings of the $5^{\text {th }}$ International Conference on Nanotechnology: Fundamentals and Applications Prague; Aug 11-13; Czech Republic. 2014.

[99] Heiskanen H, Peter D, Markku H, Paivi P, Marita O. Effect of physical properties and emulsification conditions on the microsphere size prepared using a solvent extraction process. J Dispers Sci Technol 2012; 2: 234-44.

C Subedi et al.; Licensee Bentham Open.

This is an open access article licensed under the terms of the Creative Commons Attribution-Non-Commercial 4.0 International Public License (CC BY-NC 4.0) (https://creativecommons.org/licenses/by-nc/4.0/legalcode), which permits unrestricted, non-commercial use, distribution and reproduction in any medium, provided the work is properly cited. 